\title{
Bezerra de Menezes e Gonçalves de Magalhães: muito além do cérebro. Tentativas de enfrentamento ao materialismo científico do século XIX
}

Bezerra de Menezes and Gonçalves de Magalhães:

Far Beyond the Brain. Attempts to Confront Nineteenth Century Scientific Materialism ${ }^{1}$

Artur Cesar Isaia ${ }^{*}, *$

\section{Resumo}

O artigo tem como foco de análise os estudos dos médicos Adolfo Bezerra de Menezes e Domingos José Gonçalves de Magalhães, críticos da medicina materialista. Tanto a Loucura sob novo prisma, do primeiro, quanto A alma e o cérebro, do segundo, são tentativas peculiares de enfrentamento ao materialismo científico do século XIX. Suas leituras atestam a presença da filosofia espiritualista de Victor Cousin. Trata-se de leituras que buscam superar algumas teses então em voga, como o localizacionismo cerebral e o modelo anatomopatológico. No caso de Bezerra de Menezes, trata-se de uma leitura com interface claramente religiosa, propondo uma etiologia, uma nosografia e um tratamento para a loucura fundamentados no Espiritismo. Em ambas as obras a alma aparece com centrali-

\begin{abstract}
This article focuses on the studies of the doctors Adolfo Bezerra de Menezes and Domingos José Gonçalves de Magalhães, critics of materialistic medicine. Both Loucura sob novo prisma [Madness in a new light] of the former and Alma e cérebro [Soul and Brain] of the latter are peculiar attempts to confront nineteenth-century scientific materialism. Their readings attest the presence of Victor Cousin's spiritualist philosophy. These are readings that seek to overcome some theses in vogue until then, such as cerebral localizationism and the anatomopathological model. Bezerra de Menezes' is a reading with a clearly religious interface, proposing an etiology, nosography and treatment for madness based on Spiritism. In both works the soul appears centrally, con-
\end{abstract}

\footnotetext{
* Universidade La Salle (Unilasalle), Canoas, RS, Brasil.

** Universidade Federal de Santa Catarina (UFSC), Florianópolis, SC, Brasil. arturci@uol.com.br $<$ https://orcid.org/0000-0002-7195-8027>
} 
dade, contradizendo a supremacia do cérebro como órgão responsável pelo pensamento, conforme aparecia no localizacionismo cerebral.

Palavras-chave: Espiritismo; doença mental; espiritualismo. tradicting the supremacy of the brain as the organ responsible for thinking, as it appeared in cerebral localizationism.

Keywords: Spiritism; mental disease; spiritualism.

No Brasil do século XIX, dois médicos produziram documentos defendendo a insuficiência do cérebro como sede do pensamento. Esses dois profissionais opuseram-se aos fundamentos da ciência materialista, desenvolvendo um pensamento singular a esse respeito. Um foi o cearense Adolfo Bezerra de Menezes (1831-1900)² e o outro, o fluminense Domingos José Gonçalves de Magalhães, visconde de Araguaia (1811-1882). ${ }^{3}$ Nesses dois exemplos da reação antimaterialista na medicina brasileira do século XIX encontramos em comum a disposição de repensar tanto o localizacionismo cerebral quanto o modelo anatomopatológico. Esses dois médicos não parecem ter tido o reconhecimento de seus pares, tanto à época em que publicaram suas obras, quanto posteriormente. Se a obra de Domingos de Magalhães permaneceu praticamente esquecida no debate médico, sendo o autor muito mais conhecido por sua produção artístico-literária, Bezerra de Menezes está presente na memória de boa parte da população brasileira por razões extra-acadêmicas. $\mathrm{O}$ caso de Bezerra de Menezes o singulariza pela sua experiência religiosa, que o fez conhecido como um bem simbólico do Espiritismo - o "Kardec brasileiro", praticamente pertencente a uma hagiologia nacional que extrapola o domínio confessional espírita (Warren, 1984). Inicialmente, o plano deste artigo era tratar especificamente da obra de Bezerra de Menezes. À medida que pensava no encaminhamento do texto, fui me dando conta de que não seria possível tratar com lateralidade a contribuição de Domingos de Magalhães, em razão das coabitações interdiscursivas e, igualmente, das similitudes (nas suas diferenças) das duas obras: uma leitura médico-espírita e outra médico-espiritualista da natureza humana.

\section{Bezerra de Menezes e a loucura por OBSESSÃO: INTERFACES MÉDICO-RELIGIOSAS}

O surgimento no Brasil do final do século XIX da obra A loucura sob novo prisma, de Bezerra de Menezes, acrescenta ao debate historiográfico um dado 
importante, com informações capazes de ser partilhadas entre a história das ciências e a história das religiões. Por um lado, representa a originalidade da recepção da obra de codificação espírita em terras brasileiras, por outro representa uma contribuição significativa na direção de uma leitura não organicista, materialista, centrada em teses em voga na época, como o localizacionismo cerebral e o modelo anatomopatológico. É justamente aí que se insere a sua obra, dialogando não só com o discurso médico, mas também com o filosófico e o religioso. Compreende-se o enraizamento cultural da obra de Bezerra de Menezes quando a articulamos a uma disseminada perspectiva espiritual e mágica de saúde e doença vigente no Brasil (Sampaio, 2003; Weber, 1999; Montero, 1985).

Em sua interlocução com o discurso médico na detração ao localizacionismo cerebral e ao modelo anatomopatológico, Bezerra de Menezes buscou relacionar sua obra ao redimensionamento moral da doença mental proposto por Esquirol na primeira metade do século XIX. ${ }^{4}$ Afastou-se de uma tradição amplamente aceita e difundida à época: refiro-me à tradição psiquiátrica francesa tributária de Bayle e redimensionada por Charcot (a ressignificação do localizacionismo cerebral) na segunda metade do século XIX. Nesse sentido as referências a Esquirol aparecem como recursos de autoridade a fim de corroborar a possível origem não orgânica da doença mental, ainda que Bezerra, concordando com Esquirol, não descartasse a possibilidade de loucura com fundamento orgânico (Bezerra de Menezes, 1997, p. 14).

Na obra de codificação espírita de Allan Kardec não havia a sistematização de um tratamento de desobsessão (como aparece em Bezerra de Menezes), aparecendo apenas os fenômenos descritos como obsessivos. Estes eram o resultado, segundo a doutrina espírita, da ação persecutória de espírito(s) sobre uma pessoa, capaz de afetar o seu psiquismo e até levar à doença mental. Na literatura espírita atual, Schubert (1981), a partir de obra psicografada por Divaldo Franco, para os espíritas ditada pelo espírito do baiano Manoel Philomeno de Miranda (Franco, 1978), mostrou que os processos obsessivos podiam incluir, além da ação dos espíritos sobre os "encarnados", a ação destes sobre os espíritos. A esses casos, e podendo acontecer em todos esses níveis, a obra acrescenta as obsessões recíprocas e as auto-obsessões.

Além da desobsessão, o tratamento espírita inclui, para Dalgalarrondo, a presença central dos passes, ambos muito difundidos no contexto brasileiro. Existe para o autor um repertório de doenças encaradas segundo o horizonte explicativo do Espiritismo e de amplo enfrentamento na prática espírita brasileira. Assim, os "transtornos mentais, dependência de álcool e drogas e aflições 
significativas" (Dalgalarrondo, 2008, p. 127) são enquadrados pela prática espírita brasileira na lógica do par obsessor-obsidiado e tratados pela ação conjunta das sessões de desobsessão e dos passes. Para Lewgoy (2003), a obsessão é considerada como uma categoria espírita explicitamente referente a uma "enfermidade espiritual”. Segundo o autor, a obsessão está ligada a uma teodiceia, no sentido de relacionar-se diretamente com as noções de bem e mal presentes na concepção espírita. Nesse sentido, Giumbelli (1997) analisou a força dramática do tema da perseguição espiritual constante das narrativas de obsessão.

A importância da obra de Bezerra de Menezes, aqui inquirida enquanto fonte histórica, reside em sistematizar um enfrentamento para os quadros tidos como obsessivos pela ótica espírita, trazendo-os para o campo da medicina. Nesse sentido, a sua inserção, tanto no campo religioso espírita quanto no médico, foi fundamental. Permitiu uma apropriação médica para um fenômeno como a obsessão, que se inscrevia (pelo menos no Brasil) no campo religioso, representando um caso de diluição das fronteiras entre os discursos médico e religioso. A isso se acrescenta a relação interdiscursiva com a filosofia pelo endosso do ecletismo de Victor Cousin. Se Bezerra de Menezes, na sua explicação sobre a etiologia da doença mental, transita entre o discurso médico, o religioso e o filosófico, o campo médico brasileiro da época longe esteve de reconhecer legitimidade à leitura espírita da doença mental. Por exemplo, na Faculdade de Medicina do Rio de Janeiro, uma tese de doutoramento que propôs uma etiologia da doença mental assentada nos princípios da obra de codificação espírita foi reprovada no ano de $1922^{5}$ (ver Isaia, 2007).

\section{LOUCURA E OBSESSÃO: OS PARENTESCOS}

ENTRE ESPIRITISMO E MAGNETISMO

A obra de codificação espírita foi escrita entre 1857 e $1868^{6}$ e acha-se profundamente inscrita em uma nebulosa intelectual com interfaces, tanto no positivismo, quanto no magnetismo e no ecletismo. Por um lado, a proximidade com o positivismo ligava o Espiritismo à facticidade como critério de validação científica. Por outro lado, o Espiritismo do século XIX aprofundava a ultrapassagem das fronteiras entre ciência e ficção ou entre ciência e o que Robert Darnton (1988, p. 20) chamou de pseudociência, referindo-se às hipóteses dotadas de "ressonâncias científicas" (p. 28), circulantes na França pré e pós-revolucionária. Ao analisar o outro lado do racionalismo enciclopedista francês, Darnton mostrou o consórcio entre pesquisa científica e imaginação 
ficcional. O fascínio científico da época colaborava para que a imaginação do cientista passasse a preencher as lacunas do método empírico. Assim, os microscópios, por exemplo, não apenas desvendavam um mundo oculto, mas podiam alimentar a imaginação fabulosa, apresentada como fruto do trabalho científico. Pertencem a esse terreno, já no final do século XVII, as observações em microscópio do sêmen humano feitas por François de Plantade, o qual chega a propor a existência de homúnculos, alimentando a união entre fabulação e ciência (Darnton, 1988). Jardin e Tudesq (1973) e, posteriormente, Darnton (1988) concordavam em que o frio racionalismo das luzes ia perdendo força sedutora na elite pensante pós-revolucionária. Em seu lugar aparecia o suprarracional, o cientificamente misterioso (Darnton, 1988, p. 141). Além disso, aparecia um novo racionalismo baseado na ideia de uma evolução constante, capaz de fazer do XIX o século do elogio prometeico, da revolução e da história (Jardin; Tudesq, 1973).

Inserido nesse momento de propagação do que Darnton chamou de "cientificamente misterioso", o Espiritismo surge com um discurso a um só tempo cientificista e utópico. Dessa forma, à sua projetada identidade científica articulava-se a promessa utópica de um futuro luminoso, de igualdade e fraternidade no planeta, fruto da lei do progresso contínuo (Isaia, 2001; Isaia, 2012). O Espiritismo estreitava os liames com a proposta positivista, na qual os conteúdos utópicos articulavam-se aos cientificistas ao propor uma sociedade futura cientificamente gerida (Löwy, 1998).

Darnton liga a teoria de Franz Anton Mesmer (1734-1815) - que propunha, no século XVIII, o envolvimento de todo o universo em um fluido cósmico primevo, emanado de toda forma de vida - à disposição de ultrapassar o frio racionalismo. Assim, o reino animal, vegetal e mineral, os corpos celestes e os homens relacionavam-se a esse fluido universal, capaz de explicar desde a influência dos astros na vida humana até a ascendência mental de um homem sobre outro homem (Mesmer, 1971). Para Mesmer, esse fluido magnético residia em todos os seres vivos e poderia ser ativado terapeuticamente de várias formas. Nesse sentido desenvolveram-se técnicas como os processos magnetizadores propostos pelo próprio Mesmer, além da imposição de mãos e dos passes, que se popularizariam na prática espírita brasileira.

Para Figueiredo, a doutrina do magnetismo animal "considera a existência do fluido universal, fonte primária [...] de toda a matéria. O fluido vital ou magnetismo animal seria, segundo Mesmer, um estado particular de vibração do fluido universal" (Figueiredo, 2007, p. 32). A relação entre magnetismo e Espiritismo no Brasil, com a vulgarização da prática homeopática, foi 
defendida por Warren (1986) e Arribas (2011). Para Arribas, os espíritas brasileiros consideraram a medicação homeopática como "uma forma de energia, uma espécie de fluido" (Arribas, 2011, p. 331).

A vinculação do Espiritismo do século XIX com o magnetismo animal é evidente quando a obra de codificação espírita propõe a existência de um fluido universal. A presença do magnetismo animal na leitura espírita da doença mental e, particularmente, na explicação dos quadros obsessivos é central. Sem o recurso ao magnetismo animal, não há nexo de inteligibilidade para a obsessão espírita e, consequentemente, para a leitura espírita da doença mental. É tal a importância do magnetismo no horizonte intelectual no qual se moveu o Espiritismo, que este o via como explicativo até para a compreensão dos milagres relatados no Novo Testamento. Portanto, o magnetismo aparecia mesmo na exegese espírita dos Evangelhos (Marré, 1910, p. 10). Com base no magnetismo animal é que a obra de codificação espírita propunha a existência de uma tríplice natureza humana: um corpo material corruptível e um espírito imortal envolvido por um invólucro de natureza fluídica, chamado perispírito. O corpo material, considerado análogo ao dos animais, seria animado por um princípio vital, uma alma imaterial, e haveria também o perispírito, o que estreita as homologias com o magnetismo animal de Mesmer. O magnetismo, como horizonte explicativo para o Espiritismo, aparece também na possibilidade, assumida por Kardec, de espíritos e "encarnados" participarem dos processos de cura, via emissão de fluidos tanto positivos quanto patológicos - estes, maus fluidos (Kardec, 1872, p. 316).

\section{ESPIRITISMO E ECLETISMO NO ENFRENTAMENTO}

AO MATERIALISMO CIENTÍFICO

O ecletismo de Victor Cousin representa outro ponto de referência quando se analisa o quadro intelectual no qual se moveu o Espiritismo, em razão das explícitas parcerias contra o materialismo. Se pensarmos para além do óbvio parentesco cultural, a obra de Léon Denis, tido como o sucessor de Allan Kardec na coordenação do movimento espírita francês, elogia a geração de 1848, marcada pelo ecletismo como horizonte intelectual (Isaia, 2018). É na relação com o ecletismo de Cousin que os liames entre a obra de Bezerra de Menezes e a de Gonçalves de Magalhães estreitam-se e desenvolvem correspondências. Embora Bezerra de Menezes não cite explicitamente Gonçalves de Magalhães, o endosso ao ecletismo, a própria problemática das duas obras 
e a comum negativa de considerar o cérebro como sede do pensamento une os dois autores.

Cousin propunha que a razão por si só não tinha condições de acessar a complexidade do mundo e da existência. Para ele era necessário buscar fora da razão, basicamente na sua conciliação com o sentimento e com a sensação, a forma de se captar a realidade mais harmônica com a complexidade do mundo e das criaturas. Assumindo a crença na divindade, Cousin defendia a insuficiência de todos os sistemas filosóficos, de forma exclusiva, para explicar o mundo e a natureza humana. Não é nossa culpa, escrevia Cousin, "se Deus fez a alma humana mais vasta que todos os sistemas", e se "temos a necessidade de confessar que todos os sistemas não são inteiramente absurdos" (Cousin, 1854, p. 434, trad. nossa).

No Brasil, a importância do ecletismo vai além do parentesco cultural com o Espiritismo, uma vez que permeou tanto a formação das elites pensantes da primeira metade do século XIX, quanto as próprias instituições imperiais. Paulo Mercadante (1965) e Raimundo Faoro (1976), em estudos clássicos a respeito das instituições e da formação dos homens públicos do período imperial, enfatizam a saliente presença do ecletismo. Um indício da importância do ecletismo inscreve-se na sua saliência nos programas de sociologia e filosofia do Colégio Pedro II, instituição modelar para a formação das elites políticas e intelectuais imperiais (Massimi, 1993).

Victor Cousin e o ecletismo são presenças explícitas na obra de Bezerra de Menezes. Defendendo a conciliação entre a ciência materialista e o espiritualismo, como Cousin, Bezerra de Menezes claramente referenciou o ecletismo como sistema filosófico capaz de abrir novos rumos, consorciando as descobertas científicas com a religião, capaz de dar "à questão da imaterialidade da alma o mais assinalado triunfo" (Bezerra de Menezes, 1977, p. 25).

$\mathrm{Na}$ esteira do ecletismo, para Bezerra de Menezes, "o materialismo, que, por momentos, se julgou senhor do campo, recolheu-se, corrido da filosofia e foi assentar sua tenda no terreno da ciência mal esclarecida" (Bezerra de Menezes, 1977, p. 25). Indo de encontro ao que chama de "ciência mal esclarecida" é que Bezerra de Menezes vai propor uma alternativa terapêutica e uma etiologia para os casos de loucura não acompanhados de lesão cerebral. Com isso contradizia tanto o localizacionismo cerebral, o qual encarava o cérebro como o centro irradiador do pensamento, quanto o modelo anatomopatológico, que centrava a leitura da doença mental na existência de uma lesão cerebral. ${ }^{7} \mathrm{Be}$ zerra de Menezes (assim como Gonçalves de Magalhães) contrariava, portanto, o aforismo máximo do localizacionismo cerebral cunhado por Bayle na 
primeira metade do século XIX: “onde há sintoma há lesão anatomopatológica” (Berlim; Fleck, 2001). Para Bayle, a doença mental, nos quadros em que estudou, aparecia de três formas: 1) como "sintoma de uma inflamação crônica do aracnoide"; 2) "ocasionada, mantida ou modificada por uma gastrite ou gastrenterite crônica”; 3) “determinada por uma gota irregular” (Bayle, 2009, p. 754). Portanto, quer nos casos idiopáticos quer nos simpáticos, a doença mental aparecia, para Bayle, ligada a uma lesão.

Em estreita relação com o localizacionismo cerebral e tendo como pressuposto a ideia de que o cérebro seria a sede do pensamento e das emoções, a frenologia de Gall propunha que a análise das dimensões cranianas, das suas protuberâncias, corresponderia a qualidades humanas: a anatomia do crânio, levando a um diagnóstico moral. Aparentada a essa teoria, a antropologia criminal de Lombroso vai propor a previsão da criminalidade nata nos estigmas físicos (Senderey, 1978). Essa tentativa de aliar a aparência craniana com defeitos e qualidades humanas já havia sido tentada antes de Gall, por Lavater (partindo de premissas espiritualistas) com a fisiognomia. Para Lavater, as faculdades inatas seriam lidas na forma craniana, ao passo que as características adquiridas seriam lidas nas partes moles, na pele e nas membranas (O Psicômetro..., 1842, p. 52). Para Matos (2012, p. 17) a fisiognomia é um "conhecimento antigo, caracterizado por ambivalências entre o racional e o místico e o mágico-religioso". Os parentescos intelectuais entre parceiros tão distintos quanto a frenologia (materialista) e a fisiognomia (espiritualista) mostram as itinerâncias dos discursos desafiando toda linearidade, toda previsibilidade. Dessa forma podemos ver que, para além de uma leitura meramente centrada na racionalidade e na coerência interna dos discursos, estes revelam suas imprevisibilidades, suas errâncias, traindo a delimitação de fronteiras rígidas e estanques. Essas características aparecem em Orlandi (1995, p. 127 ss), ao mostrar a itinerância dos discursos como "bólidos", com seus sentidos capazes de migrarem sem previsão. Se as fronteiras entre os discursos não são delimitadas, há nas lutas simbólicas todo um esforço identitário por traçar marcos delimitadores (Bourdieu, 1996). ${ }^{8}$ Compreende-se, assim, o não reconhecimento da academia a contribuições aparentadas às aqui analisadas. Descredenciando-as por razões "científicas", muitas vezes a academia embasava-se justamente no que Foucault (1996) chamou de teratologia do saber, referindo-se ao endosso "científico" a toda sorte de fabulações. Os exemplos existem em algumas teses de doutoramento em medicina, aprovadas no final do século XIX e primeira metade do século XX, nas quais aparecia a 
condenação às práticas espíritas, nem sempre satisfatoriamente embasadas (Isaia, 2007).

Se não bastasse a relação tecida por Bezerra de Menezes entre ecletismo e Espiritismo, um indício claro dessa relação encontra-se no acervo da $\mathrm{Fe}$ deração Espírita do Estado de São Paulo. Em meio a livros, documentos e periódicos espíritas, consta a obra A alma e o cérebro: estudos de Psicologia e Fisiologia, de Gonçalves de Magalhães. Este, considerado precursor do romantismo no país, é tido também como expoente do ecletismo brasileiro. ${ }^{9}$

\section{Bezerra de Menezes, Domingos de Magalhães}

E O ANTIMATERIALISMO

O plano das duas obras persegue o mesmo objetivo. Ambas tentam "provar" a existência de um princípio gerador do pensamento para além do cérebro. Ambas abraçam a existência anímica como uma realidade autossubsistente. Tanto a obra de Bezerra de Menezes quanto a de Gonçalves de Magalhães entram em choque com o postulado pela chamada "psicologia fisiológica" de Ribot. Esta, segundo Giumbelli, afastava-se das teses ecléticas e espiritualistas, considerando a consciência não "como uma entidade autônoma ou um atributo do ser", mas como "o produto complexo de fenômenos mais simples, um estado que despontava dentre a rede de estímulos e respostas na qual se emaranhava o sistema nervoso" (Giumbelli, 1997, p. 151). Mas as relações interdiscursivas entre Bezerra de Menezes e Gonçalves de Magalhães parecem extrapolar o terreno estrito da produção sobre o funcionamento do cérebro. À afinidade filosófica e científica entre os dois autores somam-se relações intertextuais muito próximas na produção ficcional. Por exemplo, Gonçalves de Magalhães escreveu em 1838 a peça $O J u d e u$, cuja temática era a violência inquisitorial da Igreja católica em Portugal no Antigo Regime. Essa peça tem como protagonista o dramaturgo (nascido no Brasil) e morto em Portugal Antônio José da Silva, acusado de judaísmo e condenado à morte pela Inquisição. Para Chartier (2016), a construção da narrativa mítica de Antônio José da Silva como herói nacional começa justamente com Domingos de Magalhães. Por sua vez, a temática do herói-vítima do absolutismo metropolitano e do obscurantismo religioso aproximava a obra de Domingos de Magalhães da luta pela afirmação das liberdades civis, encabeçada pelo Espiritismo na segunda metade do século XIX, sobretudo pela Federação Espírita Brasileira. A leitura da peça de Domingos de Magalhães talvez possa indiciar um 
posicionamento que ficaria claro na segunda metade do século XIX, quando vem a público a sua disputa com Varnhagen. Nessa disputa, Magalhães defendia a realidade cultural dos povos indígenas contra a detração presente na visão, simpática a Portugal, de Varnhagen (ver: Cezar, 2007; Guimarães, 1995; Tiburski, 2011). Conciliando-se com suas convicções católicas (Pinassi, 1998; Nogueira, 2017), Magalhães defendia a liberdade individual como necessária à condição humana como "ser moral" (Nogueira, 2017, p. 45), endossando uma postura intelectual cosmopolita, presente na revista Niterói (Pinassi, 1998). O próprio Bezerra de Menezes escreveu uma obra, publicada em 1890, Os carneiros de Panúrgio, na qual podemos ver relações interdiscursivas à crítica ao Antigo Regime, existentes também na peça de Domingos de Magalhães. ${ }^{10}$ Era a história de um nobre espanhol, traído pelo poder despótico real depois de descobrir terras para a Coroa no Novo Mundo. Bezerra de Menezes contrapõe a violência absolutista e religiosa a um futuro igualitário e republicano. Claro que, dados os diferentes entornos socioculturais habitados pelos dois médicos, singularidades diferenciavam as suas obras. Nesse sentido, a obra de Bezerra integrava o esforço da literatura espírita do final do século XIX e primeira metade do século XX no sentido de aprofundar um imaginário no qual se opusessem "o passado legitimista católico e o presente e o futuro, marcados pelas conquistas da racionalidade e da ciência" (aparecendo a república de forma alegórica entre essas conquistas) (Isaia, 2011, p. 117). Logicamente esse "presente e futuro" eram representados pelo Espiritismo. Já a defesa da liberdade do indivíduo na obra de Domingos de Magalhães aparecia nos limites consentidos pela monarquia, ${ }^{11}$ o mesmo acontecendo com o grupo de escritores que colaboravam com a revista Niterói (Pinassi, 1998).

Sobre a relação interdiscursiva presente na concepção de doença mental entre Bezerra de Menezes e Gonçalves de Magalhães, o argumento comum é que nem todos os casos de loucura dependiam de uma lesão cerebral, determinada empiricamente (o que ia de encontro ao modelo anatomopatológico), e que o pensamento humano não era o resultado da ação do cérebro (o que contrariava o localizacionismo cerebral). Diferenciando o cérebro da mente, "termos e conceitos considerados sinônimos até então" (Luz, 2006, p. 93), Bezerra defendia que os pensamentos originavam-se justamente na alma, tida, portanto, como princípio causal do pensamento. Com base nesses pontos de vista comuns com Domingos de Magalhães, Bezerra de Menezes propôs "demonstrar" que: primeiro, o pensamento era uma função da alma; segundo, que a doença mental podia acontecer mesmo sem a presença de qualquer lesão cerebral. A existência de casos de doença mental sem a presença de lesão 
orgânica era suficiente para comprovar, segundo Bezerra de Menezes, que o cérebro não era um órgão do pensamento. O problema central da obra de Bezerra de Menezes é o mesmo do qual partiu Domingos de Magalhães. Assim, o plano daquele autor em A loucura sob novo prisma era "determinar a natureza especial da loucura sem lesão cerebral, estabelecer as bases de um diagnóstico diferencial de uma para outra espécie, e oferecer os meios curativos deste gênero desconhecido de loucura" (Bezerra de Menezes, 1977, p. 16).

Essa tentativa de Bezerra de Menezes de sistematizar uma etiologia espiritual e um tratamento para a doença mental, trazendo-a para o âmbito nosográfico, evidencia sua obra ao confrontá-la com a codificação do Espiritismo kardequiano, em que não existe tal pretensão. Bezerra de Menezes alcança, assim, um patamar de originalidade ímpar em se tratando da recepção do Espiritismo francês no Brasil. De fato, em Le livre des médiums há um capítulo, o de número XXIII, "De l'obsession", o qual apresenta uma tipologia dos casos obsessivos, ao lado de prescrever a necessária ação moralizadora sobre o espírito obsessor. Essa ação moralizadora é desenvolvida em outra obra do Pentateuco Espírita, L'Évangile selon le Spiritisme. O enfrentamento moralizante dos casos de obsessão previsto na obra de codificação fica claro se atentarmos para o fato de que o assunto é tratado justamente no capítulo de número XXVIII, o qual apresenta uma coletânea de preces que contemplariam ocasiões especiais da existência humana, como nascimento, doenças e vicissitudes de várias ordens, inclusive a morte. A obsessão aparece como a "ação persistente que um mau espírito exerce sobre um indivíduo” (Kardec, 1872, p. 421). Entretanto, as relações entre obsessão e doenças físicas aparecem na obra de codificação, indo ao encontro da sua projetada identidade científica (p. 421).

Como o enfrentamento dos casos de obsessão deveria ser sobretudo moral, a obra de codificação prescrevia a necessidade de ambos, o espírito perseguidor e a criatura perseguida, internalizarem os conhecimentos da natureza do destino humano e da existência de Deus. Perseguindo e projetando uma identidade a um só tempo científica, filosófica e religiosa, a obra de codificação prescrevia, tanto a interiorização da doutrina trazida pelos espíritos quanto a prece, a fim de enfrentar a ação persecutória dos espíritos julgados inferiores na escala evolutiva.

Por ser um tratamento essencialmente moral, o enfrentamento da obsessão proposto pela doutrina espírita partia da necessária ação pedagógica de perseguidores e perseguidos, de obsessores e obsidiados. Dessa forma, nos alicerces da ideia de obsessão espírita estava o reconhecimento da existência do espírito como capaz de pensar, escolher e sentir, e da sobrevivência deste 
ao corpo material. E aí voltamos novamente para as relações com a obra de Domingos de Magalhães.

Já no início da sua A alma e o cérebro, Domingos de Magalhães, opondo-se principalmente à frenologia e a Gall, defendia que a unidade e a consciência do eu remetiam a um princípio não coincidente com a matéria (Magalhães, 1876, p. 1). E, avançando mais ainda na direção de uma convivência intelectual com o método fenomenológico proposto pelo Espiritismo experimental do século XIX, Domingos de Magalhães reconhecia que as relações entre espírito e matéria deveriam ser abordadas cientificamente mediante conhecimento dos fenômenos que as revelavam. Essa é claramente a posição proposta pela obra de codificação espírita ao tratar da metodologia que deveria cercar o estudo das relações entre espírito e matéria. Nesse sentido, a obra de codificação propõe partir do que é conhecido (a realidade fenomênica) para chegar-se ao desconhecido (Kardec, 1872). Mesma disposição estava presente na obra de Domingos de Magalhães ao endossar o primado da observação fenomênica na ciência como caminho para conhecer o princípio espiritual ou anímico das faculdades humanas, pois "nem as palavras espírito e matéria têm outra significação na ciência, nem nós meios temos de conhecer esses dois seres senão pelos fenômenos que revelam" (Magalhães, 1876, p. 2).

Inserido na mesma linha argumentativa e na mesma posição epistemológica, Bezerra de Menezes começou a estudar a existência da alma e sua sobrevivência à matéria de forma fenomenológica, ou seja, pelo que chamou de "manifestações anímicas, por anestesia e por sono magnético" (Bezerra de Menezes, 1977, p. 34).

Bezerra de Menezes abordou a questão da existência de um princípio distinto do corpo no ser humano de forma fenomenológica: estudando o sono anestésico provocado por meios químicos e o sonambulismo. No primeiro caso estuda o sono, a suspensão da consciência e da sensibilidade proposta pelas práticas médicas da época, ou seja, pelo uso principalmente do éter e do clorofórmio. No segundo caso, traz à tona a inconsciência e a insensibilidade provocadas pelo sonambulismo natural e pela hipnose. Prosseguindo na abordagem do que empiricamente apresentava-se como fenômeno, Bezerra de Menezes cita o relatório de Alfred Velpeau à Academia de Ciências de Paris, em 1842, no qual aparece o caso de uma paciente, submetida a sono anestésico por clorofórmio para uma cirurgia. A referida paciente, em sono anestésico, passou a discorrer sobre o que acontecia com uma amiga sua, em lugar distante. O relatório de Velpeau traz a informação de que o médico, verificando as informações com a pessoa mencionada, confirmou a veracidade dos relatos da 
paciente quando anestesiada. Na mesma direção, Bezerra de Menezes cita os fenômenos observados, entre outros, por James Braid, por Hyppolite Bernheim e por Jean-Martin Charcot, nos quais o paciente, induzido a sono hipnótico, revelava habilidades e comportamentos totalmente inexistentes quando em estado de vigília.

Seria anacrônico avaliar com os conhecimentos e valores do presente as conclusões a que Bezerra de Menezes chega ao final do século XIX e num contexto de proximidade com a sua conversão ao Espiritismo. Embora Bezerra já conhecesse a doutrina e frequentasse os espaços de sociabilidade espíritas havia mais de uma década, sua adesão pública deu-se em 1886 (Wantuil, 2002, p. 232), aparecendo A loucura sob novo prisma no final do século XIX (Luz, 2006, p. 92). Sendo assim, as conclusões a que chegou levavam as marcas do horizonte científico da época e, também, da sua biografia. Concluía que as experiências "comprovavam" a existência da alma, pois sua atividade subsistia à suspensão das atividades dos órgãos corporais. O elemento anímico, subsistindo às funções materiais, estendia assim, para Bezerra, "a vista infinitamente além do espaço, além da que pode alcançar o corpo". Assim a realidade fenomênica indicava, "à saciedade, a existência, no homem, do princípio distinto do corpo e tão distinto que, enquanto este cai em colapso, ele ostenta mais nitidamente a pujança de suas faculdades especiais" (Bezerra de Menezes, 1997, p. 35). Luz (2006) sustenta que a obra de Bezerra de Menezes aponta para uma ruptura na história da psiquiatria ao propor uma terapêutica diferencial para os casos de obsessão espiritual, rompendo com o organicismo e o materialismo.

Tanto Bezerra de Menezes quanto Domingos de Magalhães apostam na complexidade psíquica do homem. Tanto um quanto o outro, endossando o espiritualismo e a não redutibilidade do pensamento ao cérebro, pensavam o ser humano como um animal complexo, imprevisível. Aliás, os próprios fenômenos espíritas como o transe e a escrita automática relacionavam-se, para o discurso médico psiquiátrico da segunda metade do século XIX, com a ideia da complexidade psíquica humana. Esta seria sistematizada com a ideia de inconsciente, o qual passaria pelo automatismo psicológico de Janet e, principalmente, pela psicanálise de Freud. ${ }^{12}$

O paralelo argumentativo entre Bezerra de Menezes e Domingos de Magalhães é evidente mais uma vez no enfrentamento de ambos às teses materialistas que viam o cérebro como um órgão material, capaz de segregar o puramente imaterial, o pensamento. De forma clara, ambos contestavam o localizacionismo cerebral e a frenologia. Tanto na obra de Bezerra quanto na de Magalhães há a crítica às teses de Pierre Cabanis, segundo as quais o cérebro 
"segregava" o pensamento, da mesma forma que o fígado segregava a bílis. Domingos de Magalhães cita literalmente Cabanis a esse respeito, quando este afirmava que "é preciso considerar o cérebro como um órgão particular destinado a produzi-lo (o pensamento); do mesmo modo que o estômago e os intestinos são destinados a operar a digestão e o fígado a filtrar a biles" (Magalhães, 1876, p. 22).

Bezerra de Menezes e Domingos de Magalhães fazendo o contraponto ao materialismo e ao localizacionismo cerebral defendiam a necessária existência do cérebro como órgão simplesmente transmissor da origem do pensamento: a alma. Assim, Domingos de Magalhães conciliando anatomia e espiritualismo, operação bastante cara aos ecléticos, afirmava: "Podemos admitir que sirva o cérebro ao espírito como o piano ao artista que nele executa a música que tem na mente, e pode variar o toque e as harmonias, sem poder exceder a capacidade sonora do seu instrumento, que assim limita a ideia e o sentimento do artista" (Magalhães, 1876, p. 27).

A mesma linha argumentativa aparece na obra de Bezerra de Menezes, defendendo a insuficiência do cérebro como órgão capaz de pensar: "A procedência original do pensamento de um órgão material é tão repugnante, que não vale a pena combatê-la; máxima quando a doutrina espiritualista, que dá ao cérebro a simples função de órgão transmissor, satisfaz perfeitamente a razão, dando ao ser pensante - a alma - a faculdade de pensar, isto é, de elaborar o pensamento" (Bezerra de Menezes, 1997, p. 29).

Contudo, nem Bezerra de Menezes nem Domingos de Magalhães procuravam fazer um contradiscurso à ciência da sua época. O primeiro, pela óbvia razão de filiar-se a uma tradição intelectual como o Espiritismo, capaz de justamente procurar na ciência o horizonte epistemológico da sua doutrina. O segundo por tentar uma leitura científica para a relação entre consciência e cérebro, capaz de (ecleticamente) conciliar-se com a ciência da época. Nesse sentido, bem argumentou Kaori Kodama, mostrando o não afastamento de Domingos de Magalhães do horizonte científico do século XIX: "A Alma e o Cérebro era em parte uma tentativa de dar um lugar à ciência em seu pensamento, ao buscar estabelecer as relações - por meio sempre de uma hierarquia - entre os dados da matéria, sem o aniquilamento do espírito" (Kodama, 2005, p. 153). 


\section{A DEPENDÊNCIA DO CÉREBRO À ALMA}

\section{NA LEITURA ESPÍRITA E ECLÉTICA}

A alma, assim, para Bezerra de Menezes, sendo o princípio gerador do pensamento, das emoções e da sensibilidade, estaria na gênese do pensamento, das noções de identidade e moralidade. Tributário da ascendência da alma sobre o cérebro proposta por Domingos de Magalhães, Bezerra de Menezes vai sistematizar um tratamento para os casos de loucura não orgânica, com a ausência de lesão cerebral e acompanhada pela atuação de espírito(s). Segundo Bezerra de Menezes a atuação de um mau espírito sobre um ser vivo dependia da sintonia deste com os propósitos maléficos daquele. Fiel à obra de codificação espírita, Bezerra mostrava que o livre-arbítrio humano era responsável pela sintonização com espíritos que arrastavam para o mal ou que edificavam o bem. Para Bezerra, os casos de obsessão quase sempre estavam relacionados a antigas dívidas de outras existências, as quais o espírito mau, em sintonia com o pensamento já perturbado pelas emoções do obsidiado, vinha cobrar na atualidade. A maneira como o obsessor conseguia levar o obsidiado à loucura tinha uma gênese anímica, mais uma vez remetendo à aproximação com Domingos de Magalhães. É na alma, como sede individualizante do pensamento, da vontade, do sentimento, que reside o princípio capaz de estabelecer sintonia com o bem ou com o mal. Vale dizer, com os bons ou os maus espíritos. Embora Bezerra de Menezes mostrasse que havia a possibilidade de a atuação do espírito obsessor aproveitar-se de afecções orgânicas para levar à demência, isto só era possível pela sintonia anímica entre afins. O mau espírito, no afã de perturbar a razão, ora aproveitava-se de afecções morais, ora aproveitava-se de afecções orgânicas. Bezerra de Menezes recorria a Esquirol para fundamentar cientificamente a sua tese sobre a origem anímica, moral, requerente também de um tratamento moral, nos casos de obsessão espiritual: "É loucura, porque há efetivamente uma perturbação das faculdades mentais, mas não é a loucura por tal conhecida, porque esta depende da lesão orgânica do cérebro, e no caso não se dá semelhante coisa. É a loucura em que Esquirol não encontrou lesão cerebral, é a loucura psíquica” (Bezerra de Menezes, 1997, p. 141).

Como asseverava Domingos de Magalhães, o agente do pensamento era a alma, e o engenho que o possibilitava era o cérebro. Então, para Bezerra de Menezes o que havia era a interposição (para ele fluídica) do espírito obsessor entre a alma e o cérebro do obsidiado, cessando ou diminuindo a relação entre ambos. O que acontecia era que a interposição (fluídica) do obsessor entre o espírito (alma) e o cérebro do obsidiado impedia que o pensamento gerado 
pela alma usasse do cérebro para propagar-se: “A alma pensa, mas seu pensamento não pode utilizar-se do cérebro, senão imperfeitamente, por estar este truncado, alterado, em razão da barreira posta pelo obsessor, no empenho de produzir essa perturbação que se toma por loucura" (Bezerra de Menezes, 1997, p. 143).

Bezerra de Menezes desenvolveu o mesmo raciocínio perseguido por Domingos de Magalhães para "comprovar" a dependência do cérebro à alma: evidenciar a persistência de um princípio exterior ao cérebro, sede da vontade e da razão, capaz de comandá-lo e servir-se deste para transmitir as faculdades intelectuais. Nesse sentido, Domingos de Magalhães citava alguns relatos clínicos de feridos de guerra, como os de Armand Trousseau e Alfred Volpian. Esses relatos traziam a informação de dois militares com a fisiologia do cérebro comprometida, mas que mantinham, apesar disso, as suas funções intelectuais na mais perfeita ordem: "Há incontestavelmente alguma coisa além de cérebro, necessária para a explicação dessas faculdades. Há essa individualidade idêntica, que assume e reúne todas essas faculdades como atos seus próprios, e sem a qual nada perceberíamos, ainda que para o exercício de algumas de suas faculdades necessite o concurso do cérebro" (Magalhães, 1876, p. 27).

Fiel a essa linha de raciocínio, Bezerra de Menezes concluiu pela possibilidade de residir a causa de numerosos casos de doença mental na referida interposição fluídica de um espírito mau, entre a alma e o cérebro do doente. Nesses casos, o cérebro não podia obedecer ao comando da alma, resultando assim os comportamentos típicos dos doentes mentais. Bezerra de Menezes explicava essa interposição do espírito obsessor entre a alma e o cérebro do obsidiado utilizando o já referido conceito de perispírito, fiel à obra kardequiana. O perispírito seria capaz de conservar as impressões da vida material. Por conservá-las, os espíritos poderiam, segundo o seu grau de evolução, transmitir fluidos benignos ou malignos, saúde ou doença, felicidade ou desesperança. Seriam, portanto, os fluidos malignos que o perispírito do obsessor transmitiria para o obsidado, impedindo a ascendência moral da alma. $\mathrm{O}$ tratamento moralizante proposto por Bezerra de Menezes visava à elevação, pelo conhecimento, tanto do obsessor quanto do obsidiado. Além disso, Bezerra de Menezes admitia a possibilidade de um comprometimento orgânico, acompanhando a doença mental, nos casos muito graves e demorados de obsessão: "A ação fluídica do obsessor sobre o cérebro, se não for removida a tempo, dará necessariamente em resultado o sofrimento orgânico daquela víscera, tanto mais profundo, quanto mais tempo estiver sob a influência deletéria daqueles fluidos" (Bezerra de Menezes, 1997, p. 157). 
O tratamento prescrito por Bezerra de Menezes tinha, como vimos, um fundamento extremamente voltado para a aceitação, pelo obsidiado, da sua condição de espírito imortal e da contabilidade cármica a que estava, nessa condição, sujeito. A base desse tratamento era essencialmente moral, contudo poderia vir acompanhada de tratamento orgânico. Isso aconteceria nos casos em que a obsessão pudesse causar lesão no cérebro ou em outro órgão do obsidiado. Esse tratamento aparece sistematizado de forma clara, no final da obra de Bezerra de Menezes, com natureza moral e terapêutica: "No princípio, enquanto os fluidos maléficos do obsessor não têm produzido lesão cerebral, deve-se procurar elevar os sentimentos do obsidiado [...]. Alcançado este desiderato [...] deve-se evocar o do obsessor e trabalhar com ele no sentido de removê-lo da perseguição..." (Bezerra de Menezes, 1997, p. 159).

\section{CONSIDERAÇÕES FINAIS}

A leitura das relações entre a mente e o cérebro em Bezerra de Menezes e Domingos de Magalhães mostra uma comum disposição de dois médicos no enfrentamento à etiologia da doença mental de cunho materialista, na qual se inseriam as propostas do localizacionismo cerebral de Gall no início do século XIX e sua reavaliação por Broca na segunda metade do mesmo século. A herança do localizacionismo, que considerava o cérebro como a sede do comportamento e das decisões morais, obviamente não poderia ser aceita pelos dois médicos brasileiros com seus pontos de vista diferentes, mas complementares: Domingos de Magalhães, recorrendo à herança espiritualista e eclética de Cousin; Bezerra de Menezes, explicitamente trazendo o Espiritismo como horizonte explicativo para a etiologia da doença mental e, igualmente, tributário de Cousin. A recorrência de Bezerra de Menezes ao Espiritismo para a compreensão da etiologia da doença mental está ligada à ressignificação da doutrina espírita no Brasil. Para Warren (1984; 1986), Bezerra de Menezes é considerado o responsável por uma releitura da obra kardequina extremamente próxima aos valores assumidos e vivenciados pela população brasileira. Essa releitura acenava para a ideia de caridade como horizonte intelectivo do Espiritismo, capaz de amenizar tanto o cientificismo proposto na obra de codificação espírita, quanto a inexorabilidade das leis cármicas, ganhando centralidade a ação terapêutica e caritativa (Warren, 1984; Warren, 1986).

A singularidade das obras de Domingos de Magalhães e Bezerra de Menezes fica explícita não somente na negativa de ambos ao modelo anatomopatológico de doença mental e ao localizacionismo cerebral. No caso de Bezerra 
de Menezes, a etiologia espiritual proposta chega a bater de frente, implicitamente, mesmo com o redimensionamento desse modelo proposto por Jean-Martin Charcot no final do século XIX. Não encontrando lesão no sistema nervoso central das histéricas da Salpêtrière, Charcot cunhou o conceito de "lesão funcional" para explicar a etiologia da histeria, o mesmo acontecendo nos casos de histeria masculina dita "traumática", por ele estudados, portanto redimensionando o modelo anatomopatológico (Charcot, 1890, p. 450ss). Já na loucura por obsessão estudada por Bezerra de Menezes, simplesmente o autor se refere a uma possibilidade de doença mental com a ausência de lesão, colocando-se totalmente distante até mesmo da lesão funcional de Charcot.

A disposição comum de Domingos de Magalhães e Bezerra de Menezes no sentido de ultrapassarem o materialismo científico inscreve ambos em um lugar nem sempre valorizado e raramente reconhecido. O lugar lateral a que a academia relegou os dois autores é uma evidência do triunfo de outras leituras da doença mental, nas quais ambas as contribuições soam como carentes de cientificidade. Sendo assim, as duas obras impõem-se, igualmente, como documentos que dão maior inteligibilidade aos jogos de poder no interior da academia, sempre propensa a controlar e limitar a produção discursiva (Foucault, 1996), reconhecendo o que pode ser dito e o que deve ser relegado ao domínio extracientífico.

\section{REFERENNCIAS}

ARRIBAS, Célia. Espiritismo: entre crime e religião. Mneme - Revista de Humanidades, Natal, v. 11, n. 29, p. 318-339, 2011.

BAYLE, Antoine-Laurent. Pesquisas sobre doenças mentais. [1822]. Revista Latinoamericana de Psicopatologia Fundamental, São Paulo, v. 12, n. 4, p. 752-758, 2009.

BERLIM, Marcelo; FLECK, Marcelo Pio de A. Uma breve história da psiquiatria: do século XVIII à era dos tratamentos moleculares. Revista Psiquiátrica do Rio Grande do Sul, Porto Alegre, v. 33, n. 3, p. 147-158, 2001.

BEZERRA DE MENEZES, Adolfo. A loucura sob novo prisma. [1921]. São Paulo: Ed. Feesp, 1997.

BOURDIEU, Pierre. A economia das trocas linguísticas. São Paulo: Edusp, 1996.

CEZAR, Temístocles. Varnhagen em movimento: breve antologia de uma existência. Topoi, Rio de Janeiro, v. 8, n. 15, p. 159-207, 2007.

CHARCOT, Jean-Martin. Ouevres Completes. t. III. Paris: Progrès Medical, 1890.

CHARTIER, Roger. La mano del autor y el espíritu del impressor: siglos XVI e XVIII. Buenos Aires: Katz, 2016. 
COUSIN, Victor. Du vrai, du beau e du bien. Paris: Didier, 1854.

DALGALARRONDO, Paulo. Religião, psicopatologia e saúde mental. Porto Alegre: Artmed, 2008.

DARNTON, Robert. O lado oculto da Revolução: Mesmer e o final do iluminismo na França. São Paulo: Companhia das Letras, 1988.

FAORO, Raymundo. Os donos do poder. Porto Alegre: Globo, 1976.

FOUCAULT, Michel. A ordem do discurso. São Paulo: Loyola, 1996.

FRANCO, Divaldo Pereira. Sementes de vida eterna. Porto Alegre: Alvorada, 1978.

FREUD, Sigmund. Edição standard brasileira das obras completas de Freud. São Paulo: Imago, 1969.

GIUMBELLI, Emerson. O cuidado dos mortos: uma história da condenação do Espiritismo. Rio de Janeiro: Arquivo Nacional, 1997.

GUIMARÃES, Lúcia Paschoal. Francisco Adolpho de Varnhagen. In: MOTA, Lourenço Dantas (org.). Introdução ao Brasil: um banquete no trópico. São Paulo: Ed. Senac, 1995.

ISAIA, Artur Cesar. Discurso espírita e educação no contexto da laicização do estado francês. Revista Brasileira de História das Religiões, Maringá, v. 9, n. 31, p. 123-142, 2018.

ISAIA, Artur Cesar. Espiritismo, utopia e conciliação social. Cadernos do CEOM, Chapecó, v. 14, n. 13, p. 183-214, 2001.

ISAIA, Artur Cesar. Espiritismo: as imprevisibilidades do discurso. In: PEDRO, Joana Maria et al. Relações de poder e subjetividades. Ponta Grossa: Todapalavra, 2011.

ISAIA, Artur Cesar. O Espiritismo nas teses da Faculdade de Medicina do Rio de Janeiro. História Revista, Goiânia, v. 12, n. 1, p. 63-79, jan./jun. 2007.

ISAIA, Artur Cesar. A República e a teleologia histórica do Espiritismo. In: ISAIA, Artur Cesar; MANOEL, Ivan Aparecido. Espiritismo \& Religiões Afro-Brasileiras. São Paulo: Ed. Unesp, 2012.

JANET, Pierre. L'automatisme psychologique: essai de psychologie expérimentale sur les formes inférieures de l'activité humaine. [1889]. Paris: Félix Alcan, 1973.

JARDIN, André; TUDESQ, André-Jean. La France des notables: l'évolution génerale. Paris: Éd. du Seuil, 1973.

KARDEC, Allan. Le Ciel et l'enfer. [1865] Paris: Dervy, 1984.

KARDEC, Allan. L'Évangile selon le Spiritisme. [1864]. Paris: Librairie Spirite, 1872.

KARDEC, Allan. La Genèse. [1868]. Paris: Librairie Spirite, 1872a.

KARDEC, Allan. Le livre des esprits. [1857]. Paris: Dervy, 1876.

KARDEC, Allan. Le livre des médiums. [1861]. Paris: Didier, 1868.

KODAMA, Kaori. Um discurso sobre ciência, religião e liberdade no Segundo Reinado: A Alma e o Cérebro de Gonçalves de Magalhães. Revista da SBHC, v. 3, n. 2, p. 146$155,2005$. 
LEITE, Adolfo Rabello. Relação entre a matéria e os fenômenos espíritas. Salvador: Lito-Tipografia Passos, 1905.

LEWGOY, Bernardo. O mal à moda espírita: as estruturas narrativas da desobsessão. Debates do NER, Porto Alegre, v. 4, n. 4, 2003.

LÖWY, Michael. As aventuras de Karl Marx contra o barão de Münchhausen: marxismo e positivismo na sociologia do conhecimento. São Paulo: Cortez, 1998.

LUZ, Nádia. Ruptura na História da psiquiatria no Brasil: Espiritismo e saúde mental. Franca: Unifran, 2006.

MACHADO, Brasilio Marcondes. Contribuição ao estudo da Psiquiatria (Espiritismo e Metapsiquismo). 1922. Tese (Doutoramento em Medicina) - a Faculdade de Medicina do Rio de Janeiro. Rio de Janeiro, 1922.

MAGALHÃES, Domingos José Gonçalves de. A alma e o cérebro: estudos de psicologia e de fisiologia. Rio de Janeiro: Garnier, 1876.

MARRÉ, Ernest. Comment on parle avec les morts. Paris: La Nouvelle Populaire, 1910. MASSIMI, Marina. O ensino de psicologia no século XIX na cidade do Rio de Janeiro. Paidéia, Ribeirão Preto, n. 4, fev./jul., 1993.

MATOS, Maria Izilda Santos de. Espelhos da alma: fisiognomia, emoções e sensibilidades. Revista Brasileira de História das Religiões, Maringá, v. 5, n. 14, p. 15-34, 2012.

MERCADANTE, Paulo. A consciência conservadora no Brasil. Rio de Janeiro: Saga, 1965.

MESMER, Franz-Anton. Dissertation pysicho-médicale sur l'influence des planètes. [1766]. In: MESMER, Franz-Anton. Le magnétisme animal. Paris: Payot, 1971.

MONTERO, Paula. Da doença à desordem: a magia na Umbanda. Rio de Janeiro: Graal, 1985.

MOREL, Pierre. Dicionário biográfico PSI. Rio de Janeiro: Zahar, 1997.

NOGUEIRA, Marcos Eduardo. Hilemorfismo neural: as bases físicas do espírito. São Paulo: Baraúna, 2017.

O PSICÔMETRO de Portins. Revista Universal Lisbonense, Lisboa, t. II, p. 53-54, 1842.

ORLANDI, Eni Puccinelli. As formas do silêncio: no movimento dos sentidos. Campinas: Ed. Unicamp, 1995.

PACHECO, Maria Vera P. de C. Esquirol e o surgimento da psiquiatria contemporânea. Revista Latinoamericana de Psicopatologia Contemporânea, São Paulo, v. 7, n. 2, p. 152-157, 2003.

PINASSI, Maria Orlanda. Três devotos, uma fé, nenhum milagre: Niterói, Revista Brasiliense de Ciência e Artes. São Paulo: Ed. Unesp, 1998.

RANGEL, Marcelo de Mello. Gonçalves de Magalhães e a civilização do Império do Brasil através da poesia. História e Perspectivas, Uberlândia, n. 45, p. 149-192, 2011. 
SAMPAIO, Gabriela dos Reis. Tenebrosos mistérios: Juca Rosa e as relações entre crença e cura no Rio de Janeiro imperial. In: CHALHOUB, Sidney. Artes e ofícios de curar no Brasil. Campinas: Ed. Unicamp, 2003.

SCHUBERT, Suely Caldas. Obsessão e desobsessão. Rio de Janeiro: Federação Espírita Brasileira, 1981.

SENDEREY, Israel Drapkin. Manual de criminologia. São Paulo: Bushatski, 1978.

TEIXEIRA, Antonio Braz. O pensamento filosófico de Gonçalves de Magalhães. Lisboa: Instituto de Filosofia Luso-Brasileira, 1994.

TIBURSKI, Eliete Lúcia. Escrita da historia e tempo presente no Brasil oitocentista. 2011. Tese (Doutoramento em História) - Universidade Federal do Rio Grande do Sul. Porto Alegre, 2011.

WANTUIL, Zêus. Grandes espíritas do Brasil. Rio de Janeiro: Federação Espírita do Brasil, 2002.

WARREN, Donald. A medicina espiritualizada: a homeopatia no Brasil do século XIX. Religião e Sociedade, Rio de Janeiro, v. 3, n. 1, p. 88-107, 1986.

WARREN, Donald. A terapia espírita no Rio de Janeiro por volta de 1900. Religião e Sociedade, Rio de Janeiro, v. 11, n. 3, p. 56-83, 1984.

WEBER, Beatriz Teixeira. As artes de curar. Santa Maria: Ed. UFSM; Bauru: Edusc, 1999.

\section{NOTAS}

${ }^{1}$ Esta pesquisa foi financiada com Bolsa Produtividade em Pesquisa (Pq) do CNPq.

${ }^{2}$ Nascido no Ceará, vindo de uma família tradicionalmente ligada ao Partido Liberal, Bezerra de Menezes teve atuação política e parlamentar na segunda metade do século XIX. Primeiro como vereador, posteriormente como deputado na Câmara Temporária. Elemento de proa do Espiritismo brasileiro, ocupou o cargo de presidente da Federação Espírita Brasileira (FEB) durante o segundo e o quinto mandatos, representando papel harmonizador muito importante no sentido de pacificar tendências opostas no interior dessa organização (WANTUIL, 2002).

${ }^{3}$ Nascido no Rio de Janeiro, Domingos de Magalhães formou-se médico em uma época na qual a profissão longe estava de conferir status social. Desde cedo manifestou preferência pelas letras, particularmente a poesia, e pela filosofia, fundando a revista Niterói, na qual difundia o nacionalismo de viés romântico. Fez parte do núcleo de alunos de frei Montalverne, considerado introdutor do ecletismo de Cousin no Brasil. Fez carreira na diplomacia, representando o Brasil em vários Estados europeus, na Argentina e nos Estados Unidos. Sua última missão diplomática foi junto à Santa Sé (PINASSI, 1998).

${ }^{4}$ Embora enfatize uma leitura e um tratamento morais para a doença mental, Esquirol re- 
dimensionou as teses de seu professor, Pinel, vendo a etiologia das doenças mentais ligada a fatores tanto físicos quanto morais (MOREL, 1997; PACHECO, 2003).

${ }^{5} \mathrm{O}$ autor da tese foi Brasílio Marcondes Machado (MACHADO, 1922). Já a tese de Adolfo Rabello Leite (LEITE, 1905), defendida na Faculdade de Medicina da Bahia, embora tenha dado reconhecimento aos fenômenos espíritas, não menciona o Espiritismo nas "Proposições finais", onde sintetiza as conclusões às quais chegou.

${ }^{6} \mathrm{O}$ chamado Pentateuco espírita é formado por estas obras: Le livre des esprits, de 1857 (KARDEC, 1876); Le livre des médiums, de 1861 (KARDEC, 1868); L'Évangile selon le Spiritisme, de 1864 (KARDEC, 1872); Le Ciel e l'enfer, de 1865 (KARDEC, 1984), e La Genèse, de 1868 (KARDEC, 1872a).

${ }^{7} \mathrm{O}$ modelo anatomopatológico foi ressignificado na França por Jean-Martin Charcot no final do século XIX com o conceito de lesão funcional, capaz de fazer conviver a doença mental com a falta de uma lesão física.

${ }^{8}$ Bourdieu mostra o esforço por instaurar uma autoridade simbólica justamente como "um poder socialmente reconhecido de impor uma certa visão do mundo social, ou seja, das divisões do mundo social" (BOURDIEU, 1996, p. 82, grifos meus).

${ }^{9}$ Esta última assertiva não é consensual. Por exemplo, Teixeira (1994) não considera Gonçalves de Magalhães um eclético no sentido emprestado ao termo pela filosofia de Cousin. Para Gonçalves, o autor não defendia a conciliação, mas a superioridade da alma em relação ao corpo.

${ }^{10}$ Sobre a obra Os carneiros de Panúrgio de Bezerra de Menezes e sua vinculação com a luta republicana e contrária ao predomínio católico, ver Isaia (2011).

${ }^{11}$ Nesse sentido, é importante salientar a simpatia do autor pela monarquia francesa pós-revolucionária (RANGEL, 2011).

${ }^{12}$ A polêmica sobre a "paternidade" do inconsciente entre Janet e Freud acena para a sistematização da complexidade psíquica do homem, presente em ambos (FREUD, 1969; JANET, 1973).

Artigo recebido em 23 de agosto de 2019.

Aprovado em 25 de maio de 2020.

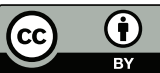

